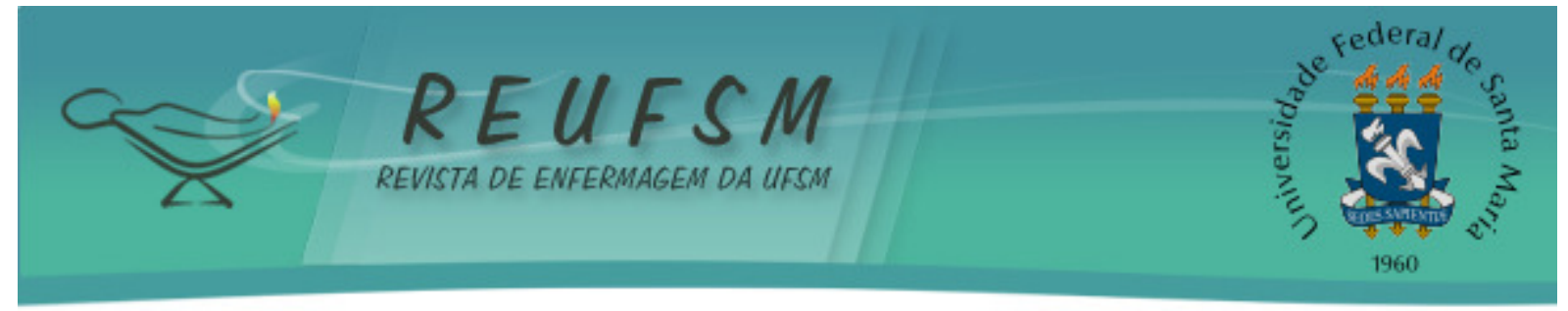

ARTIGO ORIGINAL

\title{
FATORES QUE INTERFEREM NO GERENCIAMENTO DO CUIDADO AO PACIENTE ONCOLÓGICO EM UM HOSPITAL GERAL
}

\section{INFLUENCING FACTORS OF ONCOLOGIC PATIENT CARE MANAGEMENT IN A GENERAL HOSPITAL}

\section{FACTORES QUE AFECTAN LA GESTIÓN DE LA ATENCIÓN DEL PACIENTE ONCOLÓGICO EN UN HOSPITAL GENERAL}

\author{
Caroline Cechinel Peiter ${ }^{1}$ \\ Maria Eduarda Pereira Caminha ${ }^{2}$ \\ Gabriela Marcellino de Melo Lanzoni ${ }^{3}$ \\ Alacoque Lorenzini Erdmann ${ }^{4}$
}

Doi: $10.5902 / 2179769221465$

RESUMO: Objetivo: Apontar os fatores que interferem no gerenciamento do cuidado de enfermagem aos pacientes oncológicos internados em um hospital geral localizado ao sul do país. Método: Trata-se de uma pesquisa qualitativa que utilizou a Teoria Fundamentada nos Dados, com a abordagem Straussiana para a análise dos dados. Foram realizadas entrevistas semi-estruturadas com 14 participantes: seis enfermeiros, cinco técnicos de enfermagem, um nutricionista, uma psicóloga e um familiar, no período de agosto a outubro de 2010. Resultados: Como fatores intervenientes foram identificados o gerenciamento da unidade realizado pelo enfermeiro, a dor oncológica, a necessidade de capacitações, o vínculo com a família, o relacionamento interpessoal na equipe, a nãoespecificidade da clínica e o processo de morte. Considerações Finais: Os profissionais do hospital generalista apresentam dificuldade em ofertar uma assistência direcionada e adequada à complexidade do paciente oncológico, reiterando a importância do suporte da educação continuada, interdisciplinaridade e satisfação no trabalho.

Descritores: Enfermagem; Enfermagem oncológica; Oncologia; Gerenciamento clínico

ABSTRACT: Aim: To present the factors that affect the management of nursing care to cancer patients in a general hospital located in Southern Brazil. Method: This is a qualitative study that used the Grounded Theory, with Strauss approach for data analysis. Fourteen participants have been interviewed through semi-structured interviews: six registered nurses, five nursing techinicians, one nutritionist, one psychologist and one person of patient's Family, from August to October 2010. Results: As intervening factors, it was identified: management unit performed by nurses, cancer pain, the need for training, bonding with family, interpersonal relationships on the team, the non-specificity of the clinic, and the process of death. Conclusion: The general hospital professionals have difficulty in offering a specific and appropriate care to the cancer patient, reaffirming the importance of the support of continuing education, interdisciplinarity and job satisfaction.

Descriptors: Nursing; Oncologic nursing; Medical oncology; Disease management

\footnotetext{
${ }^{1}$ Enfermeira. Mestre em Saúde Coletiva. Universidade Federal de Santa Catarina. Florianópolis/SC, Brasil. carolcechinel@gmail.com

2 Enfermeira. Especialista em Saúde da Família - modalidade residência. Universidade Federal de Santa Catarina. Florianópolis/SC, Brasil. maria_caminha@hotmail.com

${ }^{3}$ Enfermeira. Doutora em Enfermagem. Universidade Federal de Santa Catarina. Florianópolis/SC, Brasil. gabimrc@gmail.com

${ }_{4}^{4}$ Enfermeira. Doutora em Enfermagem. Universidade Federal de Santa Catarina. Florianópolis/SC, Brasil. alacoque@newsite.com.br
} 


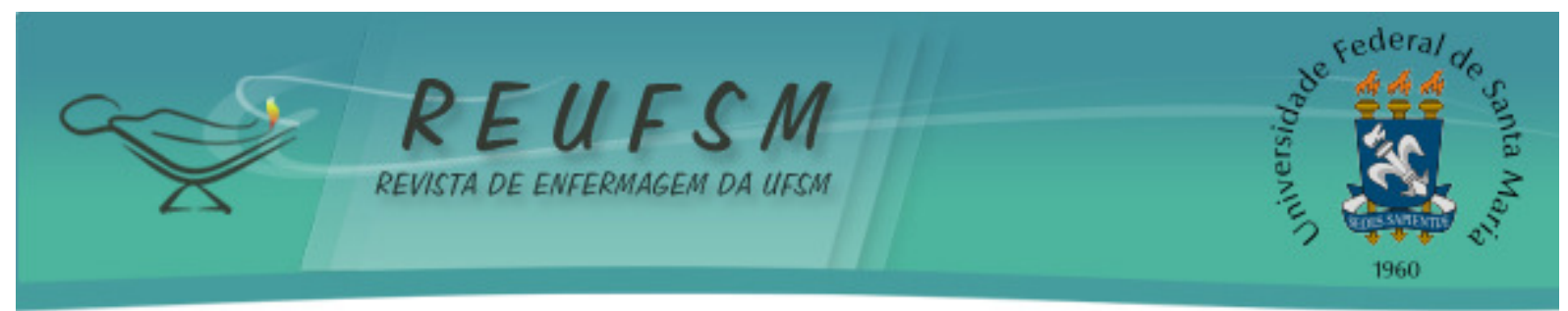

RESUMEN: Objetivo: Presentar los factores que intervienen en la gestión de los cuidados de enfermería de pacientes con cáncer en un hospital del sur del Brazil. Método: investigación cualitativa que utilizó la Teoría Fundamentada (GroundedTheory), con el enfoque de Strauss en el análisis de datos. Fueron entrevistados 14 participantes con entrevistas semiestructuradas: seis enfermeros, cinco técnicos, una nutricionista y un psicólogo, y un familiar, de agosto hasta octubre 2010. Resultados: Los factores identificados fueron: la gestión de la unidad realizada por los enfermeros, dolor por el cáncer, la necesidad de formación, la relación con la familia, las relaciones interpersonales en el equipo, la no especificidad de la clínica, y el proceso de la muerte. Conclusión: Los profesionales tienen dificultades para ofrecer una asistencia específica y adecuada a la complejidad de los pacientes, reiterando la importancia del apoyo de la educación continua, interdisciplinaria y la satisfacción laboral.

Descriptores: Enfermería; Enfermería oncológica; Oncología Médica; Manejo de la enfermidad

\section{INTRODUÇÃO}

O exercício legal da Enfermagem é respaldado pela Lei 7.498/86 que apresenta planejamento, organização, coordenação, execução e avaliação dos serviços de assistência como atividades do enfermeiro, demonstrando o importante papel deste profissional na gerência assistencial de serviços de saúde. ${ }^{1}$

As atribuições do Enfermeiro se redirecionam, visando não apenas responder às necessidades da demanda, mas também instituir uma atividade assistencial baseada em um planejamento prévio, atuando de forma cada vez mais científica. Um cuidado pensado e sistematizado facilita e qualifica o trabalho da equipe de enfermagem, favorecendo a autonomia e o reconhecimento da profissão. ${ }^{2,3}$

A complexidade técnico-científica e emocional necessária frente ao cuidado em saúde exige um gerenciamento do cuidado esmerado, demandando do enfermeiro atenção no momento de sistematizar a assistência a ser prestada. Especialmente, o paciente oncológico necessita receber um cuidado específico e competente em toda a sua complexidade e amplitude, baseado em evidências científicas confiáveis e atuais, objetivando a qualificação da assistência. ${ }^{4}$

A assistência ao paciente oncológico é uma tarefa delicada na prática clínica do Enfermeiro. 0 esclarecimento de dúvidas acerca do diagnóstico, e orientações referentes ao tratamento são atribuições esperadas deste profissional, de modo que seu papel educativo é atribuição necessária para manejo do paciente com câncer. Dessa forma, é fundamental seu entendimento sobre os diversos aspectos da doença, o que contribui para a melhor convivência do paciente e sua situação de saúde. ${ }^{5}$

Em instituições especializadas a assistência de enfermagem pode ser mais facilmente organizada, podendo ser gerenciada e aplicada à situação clínica apresentada com mais frequência pela demanda, haja vista que todos os indivíduos hospitalizados exigem uma linha de cuidado aproximado. Isso facilita o trabalho do enfermeiro, que pode aprofundar seus conhecimentos e aperfeiçoar o uso da metodologia da assistência. ${ }^{4,5}$

Entretanto, em instituições generalistas os pacientes apresentam as mais variadas alterações do estado de saúde, dificultando a especificidade do cuidado, bem como a aplicação de uma assistência de enfermagem que atenda a todas as necessidades biopsicossociais apresentadas de forma particular para cada indivíduo. ${ }^{4,5}$

Percebe-se, então, a necessidade da ampliação dos conhecimentos para identificação dos elementos intervenientes no planejamento da assistência ao paciente oncológico no cotidiano da enfermagem atuante em uma instituição generalista. A partir do contexto 


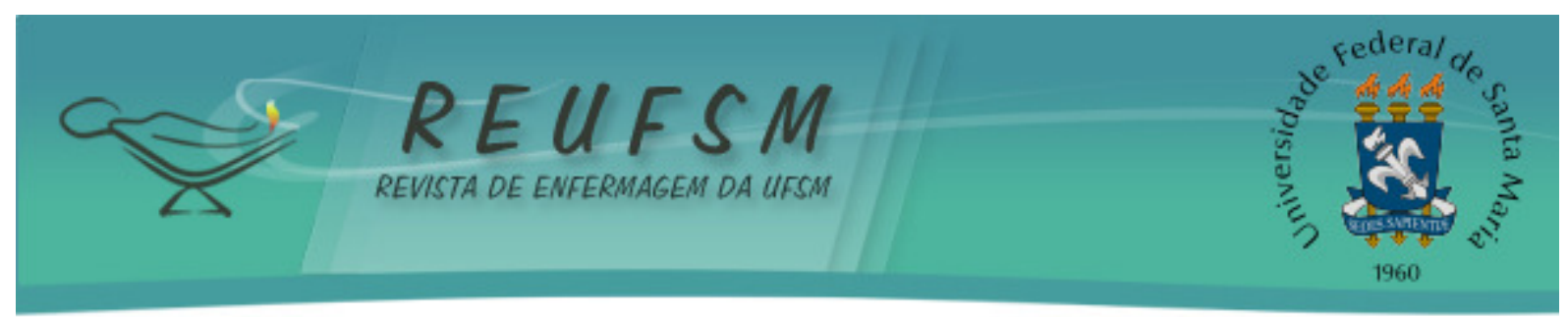

apresentado, questiona-se: Quais os fatores que interferem no gerenciamento do cuidado de enfermagem aos pacientes oncológicos internados em um hospital geral localizado ao sul do país? Assim, este estudo teve como objetivo apontar os fatores que interferem no gerenciamento do cuidado de enfermagem aos pacientes oncológicos internados em um hospital geral localizado no sul do país.

\section{MÉTODO}

Trata-se de uma pesquisa de natureza qualitativa, que adotou como referencial metodológico a Teoria Fundamentada nos Dados (TFD), mundialmente conhecida como Grounded Theory. Originalmente desenvolvida por sociólogos americanos, a TFD visa construir uma teoria assentada nos dados a partir da exploração do fenômeno na realidade em que o mesmo se insere, sendo que a construção teórica explica a ação no contexto social. ${ }^{6}$

Os dados foram coletados no período de agosto a outubro de 2010, após a assinatura do termo de consentimento livre e esclarecido (TCLE). O cenário selecionado para o desenvolvimento da pesquisa foi a Unidade de Internação Médica de um hospital geral localizado ao sul do país, que possui em média $20 \%$ dos seus 30 leitos ocupados por pacientes oncológicos. A unidade foi escolhida pela alta frequência com que recebe pacientes oncológicos.

Os participantes foram escolhidos a partir da amostragem teórica, processo em que o pesquisador decide, a partir das respostas e hipóteses de pesquisa, onde e com quem buscar as informações relacionadas ao fenômeno de investigação. Este processo possibilita a formação de grupos amostrais, com sujeitos que demostravam significativa contribuição como informantes sobre a temática. ${ }^{6}$

Assim, o primeiro grupo amostral foi composto por seis enfermeiros (um gerencial e cinco assistenciais) das Unidades de Internação Médica, cujos depoimentos geraram questionamentos sobre a importância da equipe de enfermagem e da equipe multidisciplinar. Formou-se, então, o segundo grupo amostral, constituído por cinco técnicos de enfermagem. Com este grupo foi possível fortalecer algumas categorias e gerar mais hipóteses, a mais importante delas e geradora do grupo amostral seguinte foi: a equipe multiprofissional integrada e a participação familiar promovem um cuidado mais qualificado. Assim, o terceiro grupo amostral foi formado por um familiar de um dos pacientes oncológicos internados na clínica, juntamente com um psicólogo e um nutricionista, totalizando 14 sujeitos. A formação de novos grupos amostrais foi complementando e consolidando as categorias à medida que avançavam.

Os dados foram coletados por meio de entrevistas semi-estruturadas e uma pergunta inicial: "Para você, qual o significado do gerenciamento do cuidado ao paciente oncológico? Quais ações e interações influenciam este processo?”. O encaminhamento das demais questões foi direcionado pelas pesquisadoras, a partir das respostas dos entrevistados, levando-os a refletirem sobre suas práticas e o desenvolvimento do seu fazer em saúde.

Cabe ressaltar que na TFD os dados são coletados e analisados, concomitantemente. A análise foi estruturada em três etapas: codificação aberta, axial e seletiva. A codificação aberta é o primeiro passo para a análise, consistindo em separar, examinar, comparar e conceituar os dados obtidos. Assim, o processo analítico envolveu a codificação de todos os dados obtidos linha a linha, transformando cada fala do entrevistado em um código, sendo em seguida agrupados por semelhanças e diferenças. O segundo passo da análise é a codificação axial, onde os códigos preliminares foram agrupados, gerando conceitos e categorias. A codificação seletiva é a busca e desenvolvimento da categoria central ou fenômeno, em torno da qual giram todas as demais categorias. ${ }^{6}$ 


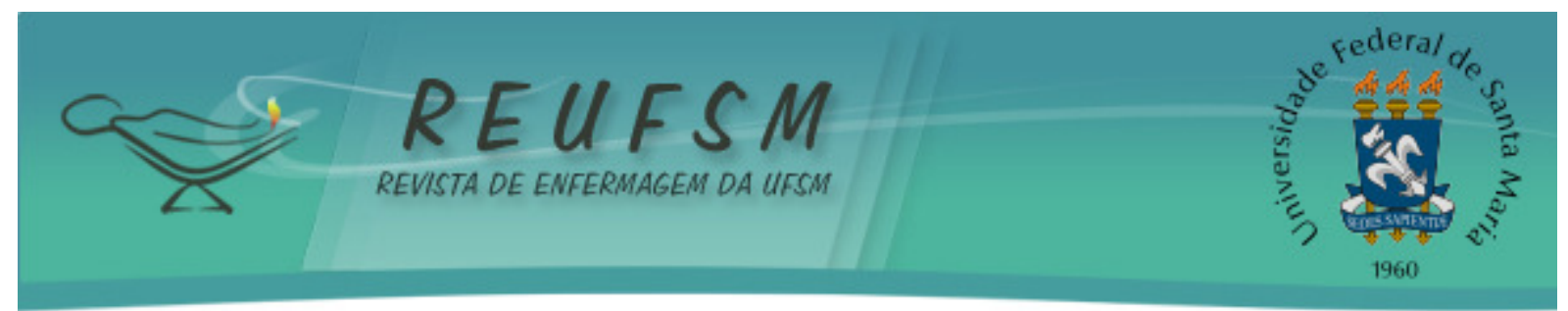

O avançar metodológico e o aprofundamento conceitual por meio das entrevistas subsequentes permitiram o surgimento do fenômeno: "Percebendo a superação do profissional e a importância da interdisciplinaridade ao contrastar o gerenciamento do cuidado de enfermagem humanístico e humanitário preconizado ao paciente oncológico com o vivenciado pelos profissionais de saúde e familiares em uma unidade de internação hospitalar geral".

As categorias foram organizadas segundo o Modelo Paradigmático, que estabelece uma relação entre o fenômeno e as categorias, identificando-as como Contexto, Condições Causais, Condições Intervenientes, Estratégias de Ação/Interação ou Consequências. ${ }^{6}$ Dada a importância e relevância das Condições Intervenientes, optou-se por analisá-las separadamente neste trabalho, haja vista a riqueza dos dados desvelados e por constituirse em um importante material para repensar as práticas de enfermagem.

A pesquisa teve início com o parecer favorável do Comitê de Ética em Pesquisa em Seres Humanos da Universidade Federal de Santa Catarina (UFSC), registrado sob o número $897 / 10$, seguindo os preceitos éticos da Resolução 196/1996. ${ }^{7}$ A identidade dos entrevistados foi preservada, sendo suas falas identificadas no texto pela categoria profissional seguida de um número sequencial atribuído a cada um deles.

\section{RESULTADOS}

As categorias relacionadas às condições intervenientes foram: Percebendo as influências do relacionamento interpessoal dentro da equipe de enfermagem sobre o cuidado; Trabalhando o vínculo com a família e seus enfrentamentos; Percebendo a necessidade de capacitações para a equipe de enfermagem.

Percebendo as influências do relacionamento interpessoal dentro da equipe de enfermagem sobre o cuidado

Esta categoria é sustentada por três subcategorias: "Destacando o enfermeiro no processo de cuidado e gerência na unidade de internação", "Cuidando de pacientes oncológicos" e "Levando conhecimentos ao paciente".

Destaca-se que um bom entrosamento entre a equipe proporciona um melhor cuidado ao paciente, fomentando momentos de discussão e busca de melhores práticas de cuidado, como evidencia a fala:

de um modo geral a equipe quando está entrosada, seja o tipo de paciente que for, presta um cuidado melhor ao paciente. A gente nota isso desde a facilidade em pedir ajuda em um momento de necessidade do profissional, até nos momentos de troca de conhecimento, que acontece geralmente quando a equipe está tomando café, tendo conversas informais. (Enfermeira 3)

Assim, a atuação do enfermeiro como dirigente da unidade de internação foi considerada fundamental, sendo reconhecida e valorizada na instituição por sua atitude resolutiva, capacidade de articulação e postura interdisciplinar, como pode ser observado nas seguintes falas:

então os demais profissionais que atuam aqui, uma hora ou outra eles são obrigados a procurar o enfermeiro pra saber alguma coisa. Sempre o ponto de referência da unidade é o enfermeiro. [...] Aqui tem uma cultura de respeito para o profissional enfermeiro. (Enfermeira 1) 


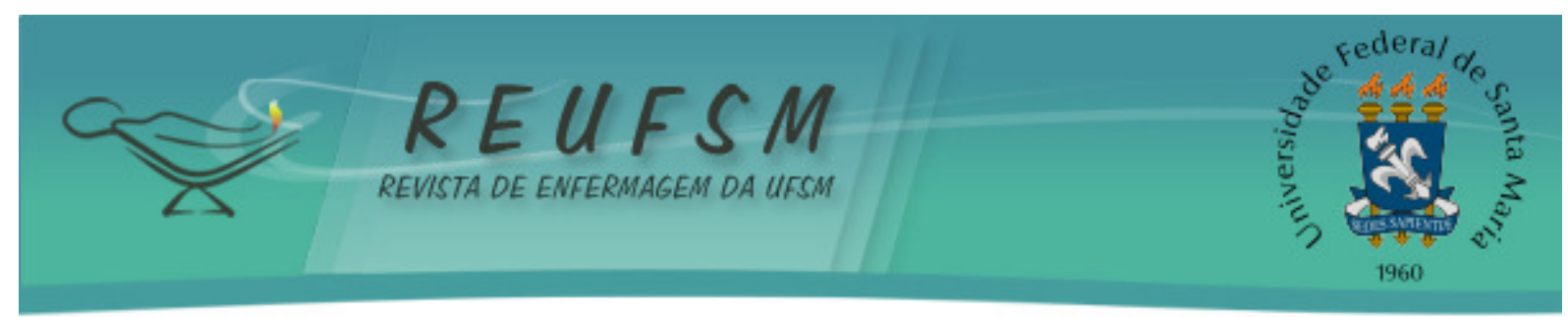

eu acho que a enfermeira pode ajudar bastante o trabalho da gente [equipe multiprofissional], no sentido de ajudar a avaliar esse paciente, também nos trazer dados. Porque é a enfermagem que está ali na linha de frente, que está 24 horas com o paciente, é a que pode nos dar mais informações. (Psicóloga 1)

Em relação ao gerenciamento, pode-se perceber ainda a importância atribuída pelos profissionais sobre o relacionamento interpessoal, influenciando positivamente na assistência prestada ao paciente. Decisões importantes muitas vezes são levadas para discussão em equipe, caracterizando um planejamento participativo e efetivo como traz a fala a seguir:

quando têm várias situações de funcionários faltando, ou paciente mais grave, paciente menos grave, a gente acaba decidindo junto, junto com a equipe. E isso pra eles eu acredito que é bom porque não fica aquela coisa imposta, verticalizada, assim, normas $e$ regras. (Enfermeira 1 )

Atuar em um hospital generalista, oferecendo cuidado direto a pacientes oncológicos, resgata a reflexão sobre quais necessidades de uma assistência diferenciada devem ser destinadas aos mesmos. 0 paciente oncológico necessita de uma assistência que the traga conforto e muitas vezes, por falta de conhecimento do profissional, este cuidado não é realizado de maneira apropriada.

A gente só começa a perceber que tem que ter os cuidados quando os problemas começam a aparecer. Não temos na nossa mente, tá agora ele vai começar com enjoo por causa do quimioterápico, vai começar com falta de apetite, não pensamos nisso. Só vamos pensar na hora que começar a ter a reação. (Enfermeira 4)

Um diferencial seria, no meu entendimento, deixá-los em uma unidade específica né, não misturados com outras especialidades. Como aqui é uma unidade mista, com várias especialidades, não temos um atendimento diferenciado. Para ser diferenciado acho que deveria ser especializado naquela área e treinar as pessoas para aquilo. (Técnico de Enfermagem 3)

Além disso, trabalhar com o paciente oncológico significa além de tudo, sanar as dúvidas do paciente e da família frente à nova doença, repleta de estigmas e preconceitos. Faz-se necessário, então, permitir o conhecimento para este paciente, tirando suas dúvidas e ofertando uma explicação fácil de ser compreendida sobre seu estado de saúde. Foi revelada pelos participantes a existência de uma grande dificuldade em lidar com estes questionamentos.

Eu não gosto de fazer esta parte, mas eu faço. Não tem outra pessoa que possa fazer. Se não for eu, vai ser outro enfermeiro, então eu vou. Mas é por obrigação, mesmo. Não é algo que eu me sinta segura em fazer. Eles sempre têm dúvidas que a gente não sabe responder corretamente, então eu acabo respondendo o que eu acho. É muito específico. Cada caso é um caso. (Enfermeira 3) 


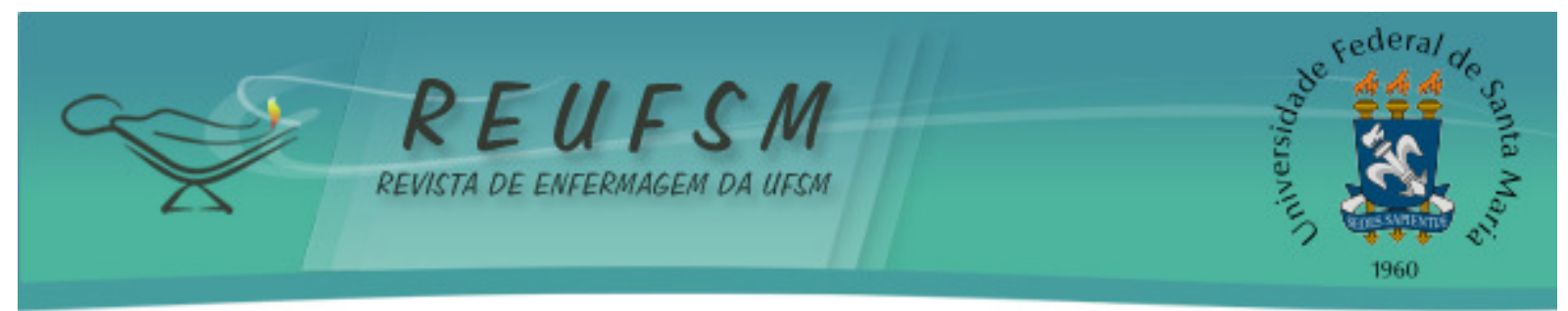

Evidencia-se, assim, a necessidade da especificidade da assistência a estes pacientes, direcionando o foco de cuidado, o que levaria a um aprofundamento de conhecimentos dos profissionais envolvidos.

\section{Trabalhando o vínculo com a família e seus enfrentamentos}

Nesta categoria se observou a importância do incentivo à família na participação do processo saúde-doença do paciente. Ancorada em duas subcategorias: "Percebendo as dificuldades para a família"e "Confortando a família no processo de morte". Os dados revelaram que estes vínculos se tornam ainda mais fortes após o diagnóstico, notando-se claramente os benefícios do suporte familiar a este paciente. É de responsabilidade do enfermeiro, enquanto gerente da equipe, perceber quando os funcionários não estão facilitando e incentivando o acesso e a permanência da família junto ao paciente, como mostra a fala:

e em relação a isto [vínculo com a família e seus enfrentamentos] eu sinto vontade de trabalhar alguma coisa na clínica ainda, com os nossos funcionários. Uma melhor receptividade da família, para serem mais compreensivos. (Enfermeira 2)

A principal forma de atuação do profissional frente ao processo de morte se dá em proporcionar condições dignas no momento de finitude, bem como suporte emocional à família. Acolher o familiar e facilitar sua presença junto ao paciente leva a um sentimento de maior conforto e segurança, promovendo maior bem-estar nesse momento.

Neste momento quase sempre o que é mais importante na vida do paciente é a família. Porque tem o medo da perda, o medo de deixar esta família, a família com medo de perder este paciente. Então é tentar deixá-los cada vez mais próximo. (Enfermeira 2)

O preconceito da associação da doença oncológica com a morte se dá devido às altas incidências de óbito devido ao câncer. Isso aumenta ainda mais a preocupação do paciente e da família, levando a um olhar mais atento do profissional influenciado pela compaixão.

Porque as pessoas associam: câncer e morte. Querendo ou não todo mundo associa, então tu tens que ter esta sensibilidade até para mostrar para eles que não é assim. Que muita gente faz seu tratamento e fica curado, e fica bem, que não é uma sentença de morte e muitos profissionais acham isso também, que o câncer é uma sentença de morte. $E$ aí tu acabas refletindo isso para o paciente no teu cuidado "-Ah, não tem mais nada para ti fazer", claro que tem sempre tem alguma coisa para fazer. (Enfermeira 5)

\section{Percebendo a necessidade de capacitações para a equipe e enfermagem}

As subcategorias "Percebendo a importância de treinamento na área oncológica", "Falando sobre a importância da formação para o enfrentamento do óbito" e "Contrastando a preocupação com a dor e os preconceitos com analgesias" deram origem a esta categoria. 


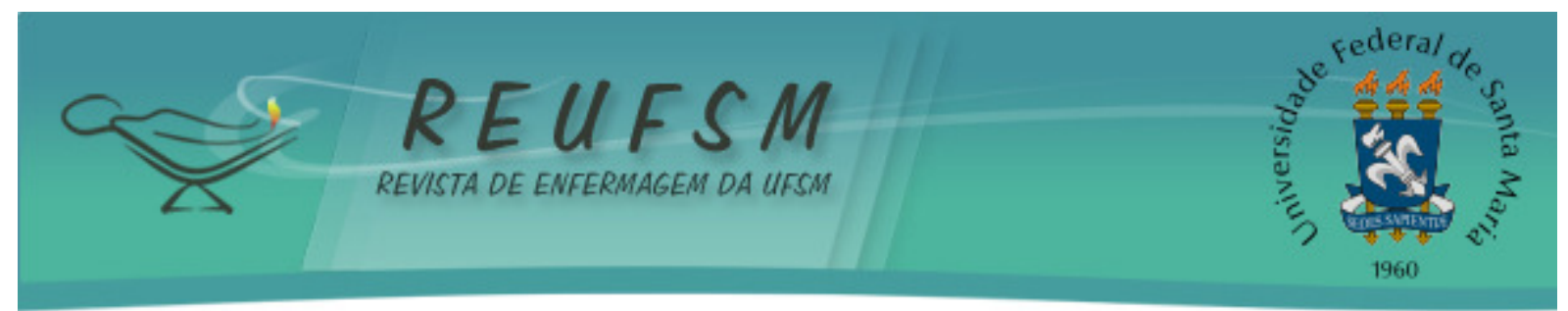

Em diversos momentos se revelou a importância de frequente atualização nos assuntos ligados à saúde. Devido às mudanças e aprimoramentos contínuos, cada vez se fazem mais necessários a melhora de conhecimento e constantes capacitações.

Os profissionais evidenciaram a especificidade da oncologia, tratando-se de um tema que deveria ser melhor abordado entre os profissionais da saúde que trabalham na área. Treinamentos com a equipe, discussões sobre os casos presentes na clínica, formas de cuidar este paciente, ações para melhorar seu conforto, atitudes profissionais frente à dor, processo de morte e interação com a família foram apresentados como deficitários no cuidado por não serem abordados com a equipe. A fala a seguir demonstra a percepção do profissional sobre a importância destas atualizações:

acho que isto [formação específica] seria fundamental para que nós aprendêssemos realmente a valorizar as queixas. A saber, entender o que se passa na cabeça de um paciente que recebe este diagnóstico. (Enfermeira 2)

O enfermeiro tem o papel de identificar as áreas deficientes no conhecimento da equipe e providenciar métodos de atualização conjunta visando o crescimento intelectual e, consequentemente, a qualificação do cuidado prestado.

Uma das maiores aflições dos profissionais entrevistados pode ser evidenciada nesta categoria, em que se percebe o medo de administrar medicações analgésicas, muitas vezes aguardando o agravamento da dor. Foram reveladas também as angústias de toda a equipe frente à dor do paciente oncológico, gerando contradição e ambiguidade de sentimentos na equipe, como traz a fala:

porque o paciente oncológico é um paciente que quase sempre tem muita dor. $E$ a gente [...] e a maioria das pessoas reconhece que $o$ paciente está com muita dor e acaba meio que justificando que esta dor é inerente de quem tem câncer e que por isso é tão doloroso. Mas não procura melhorar a questão da analgesia. E eu percebo isso não só na equipe de Enfermagem. A equipe médica também tem muita cautela na hora de prescrever a medicação pra dor, fica protelando muito. (Enfermeira 2)

O manejo da dor foi considerado uma importante prática para o gerenciamento do cuidado. No entanto, para se tornar um elemento facilitador e superar as dificuldades supracitadas, necessita mais do que o exercício de técnicas assistenciais, demandando um olhar ampliado, sensível, bem como capacitação contínua.

\section{DISCUSSÃO}

As vertentes assistenciais e gerenciais se encontram no processo de trabalho do enfermeiro, integrando conhecimentos empíricos proporcionados pela prática com o respaldo teórico, a fim de garantir um cuidado com segurança e eficiência. ${ }^{4}$

Para efetivação de um gerenciamento em enfermagem, é imprescindível a contribuição que cada um dos membros da equipe tem a fazer, não só no sentido de simplesmente apontar acertos ou falhas, mas também de participar de todos os processos passíveis de soluções do grupo, delineando estratégias de aperfeiçoamento e reorganizando atividades e serviços. A participação da equipe em seu processo de avaliação permite o aprendizado, a melhoria e a identificação dos pontos fortes e fracos existentes. ${ }^{8}$ 


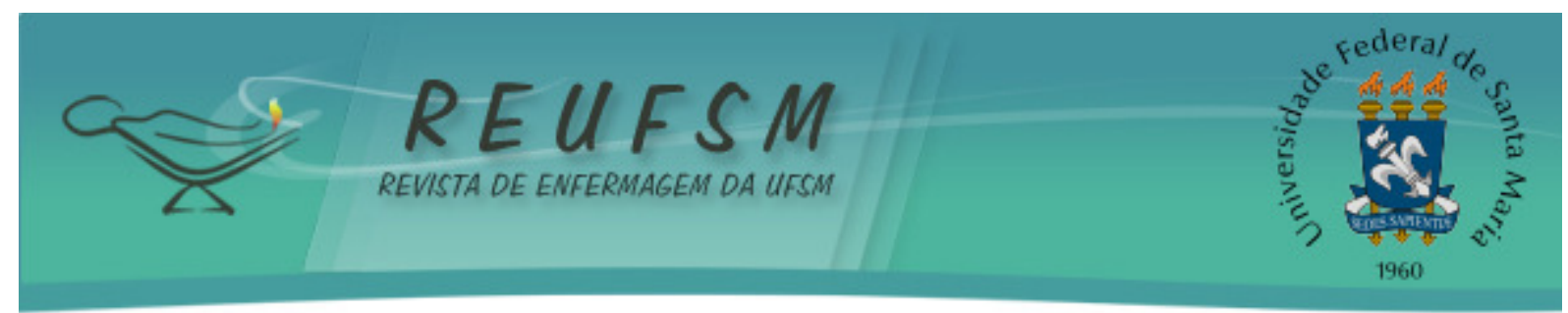

O relacionamento entre os profissionais da equipe de saúde exige do enfermeiro atenção especial no gerenciamento destas relações. A fim de qualificar a assistência prestada, o enfermeiro utiliza a liderança como um instrumento em seu processo de trabalho gerencial, auxiliando no gerenciamento de conflitos e na supervisão da equipe. ${ }^{9-10}$

Este gerenciamento deve ser entendido como ação inserida no processo assistencial e também gerencial da enfermagem. A supervisão deve ser realizada empregando um método de ensino, uma vez que tem papel fundamental no gerenciamento da assistência, e o enfermeiro, como líder de sua equipe, deve exercê-la continuamente, propiciando aprimoramentos no cuidado dispensado ao paciente. ${ }^{11}$

Cuidar de pacientes com patologia específica, como o câncer, exige do profissional clareza sobre as principais características, sinais e sintomas dos agravos e possibilidades de intervenção para favorecer seu estado de saúde. Assim, o acesso do paciente às suas informações de saúde pode promover tranquilidade e confiança. ${ }^{12}$

Informar o paciente é uma obrigação do profissional de saúde e uma condição necessária para proporcionar sua autonomia. Entretanto, o acesso a essas informações deve respeitar diversos aspectos, considerados humanitários. O profissional deve respeitar os preceitos éticos e legais, esclarecendo o paciente sobre sua saúde. Entretanto, deve ter discernimento suficiente para não the causar traumas ou danos maiores devido ao não entendimento da informação recebida. ${ }^{12}$

Apesar do desgaste físico e emocional, a família se organiza para cuidar do integrante doente, e presta esse cuidado respeitando as suas limitações, auxiliando sobremaneira no enfrentamento da doença. Esta rede se configura como fonte de apoio nas diferentes etapas da doença vivenciadas, servindo também de elo nesse processo de comunicação. $^{13-14}$

0 enfermeiro deve enxergar a família como parte da assistência, buscando compreender e reconhecer a capacidade de enfrentamento dos envolvidos, tendo-a como uma aliada nesse processo, uma vez que uma rede de apoio orientada para o cuidado poderá atuar positivamente junto à recuperação. Assim, a Enfermagem tem um papel importante frente ao fortalecimento de vínculo do paciente e família, reduzindo ansiedades e sofrimentos, e promovendo assim seu bem-estar físico e psíquico. ${ }^{13-14}$

Logo, cuidar de paciente oncológico implica ao profissional de enfermagem prestar cuidado a toda a família. 0 câncer é considerado uma doença familiar, sendo que quando um membro tem a doença diagnosticada, a vida de todos os outros é alterada de alguma maneira. Dessa forma, é indispensável que o enfermeiro desenvolva um plano de cuidados com foco na dimensão emocional e psicossocial sobre todos os membros da rede familiar, tendo em vista a recorrente associação que se faz entre o câncer e a morte. ${ }^{15}$

Neste cenário, é preciso considerar a percepção da dor pelo profissional de saúde em uma dimensão mais ampla, que inclui as atitudes e expectativas do paciente, seu sistema de crenças, e o apoio da rede familiar. Entretanto, muitas vezes a dor é tratada por meio da negação do profissional por não conseguir suprimi-la com analgésicos. A avaliação imprecisa dos quadros álgicos e a utilização insuficiente de medicações analgésicas disponíveis implicam no controle inadequado da dor. Outro problema relacionado é o preconceito para com o uso de medicamentos opióides e falta de conhecimento com relação ao manejo da dor na equipe de saúde, reflexos diretos do déficit de conhecimento do profissional. ${ }^{15}$

Como estratégia para a manutenção da qualidade do cuidado de forma geral, a Educação Permanente em Saúde (EPS) constitui-se uma ferramenta fundamental às transformações do trabalho no setor, para que venha a ser lugar de atuação crítica, reflexiva, propositiva, compromissada e tecnicamente competente. A EPS é destinada a 


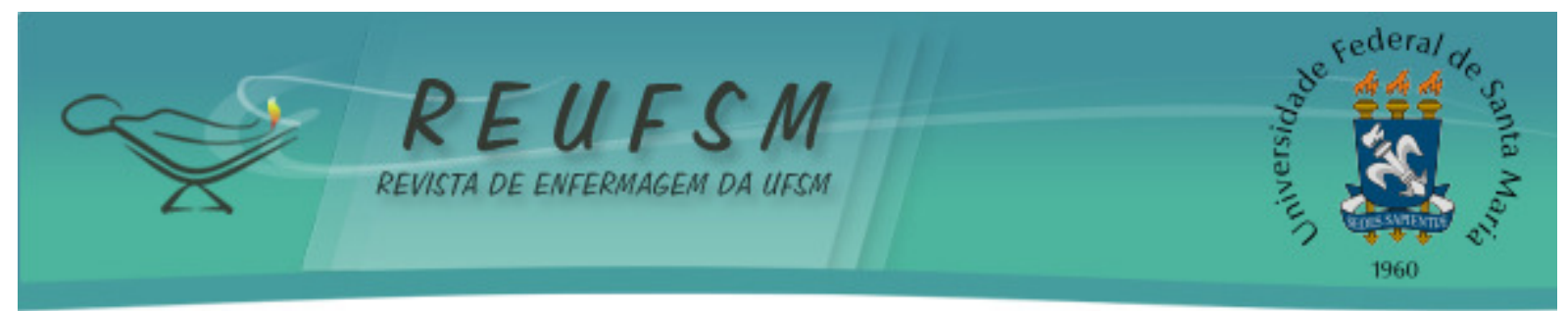

desenvolver e atualizar conhecimentos, reciclar saberes e capacitar o profissional ao ambiente de trabalho, qualificando os serviços prestados aos pacientes. ${ }^{16}$

A temática da EPS depende da demanda que surge como uma necessidade do ambiente de trabalho, sendo abordada de forma horizontal e interdisciplinar, e de acordo com a realidade do serviço. Objetiva o aperfeiçoamento relacionado ao cotidiano da equipe, e consequente o aperfeiçoamento da assistência prestada. Cabe ao enfermeiro identificar as necessidades e interferir nesse processo, abordando a temática proposta no intento de qualificar a equipe. ${ }^{16}$

\section{CONCLUSÕES}

O gerenciamento do cuidado de enfermagem é reconhecido como método para alcance de um cuidado mais especializado e, consequentemente, mais adequado ao paciente oncológico, suscitando a qualificação da assistência prestada.

Como fatores que interferem no gerenciamento desse cuidado especializado foram apontadas como responsabilidade do enfermeiro: a identificação e as condutas adequadas a serem tomadas frente à dor; a necessidade de capacitações bem como as dificuldades vivenciadas pela falta destas; o vínculo que o profissional necessita formar com a família para proporcionar sua aproximação; as influências do relacionamento interpessoal entre os funcionários da equipe sobre o cuidado prestado; o fato de o hospital ser uma instituição generalista; e a conduta adequada do profissional diante do processo de morte.

Embora este estudo tenha sido realizado em uma unidade de internação de um hospital geral, seus achados podem orientar a prática da enfermagem, buscando uma assistência de qualidade baseada no conhecimento dos fatores intervenientes da assistência ao paciente oncológico, com o suporte da educação continuada, interdisciplinaridade e satisfação no trabalho.

Ainda, como outra importante contribuição da atuação do enfermeiro generalista no cuidado ao paciente oncológico, destaca-se a atuação como coordenador do cuidado, com ênfase no trabalho resolutivo, capacidade de articulação e postura interdisciplinar que potencializam resultados positivos na interação entre os profissionais frente ao processo de morte e boa aceitação de práticas de capacitação profissional.

Sugere-se para pesquisas futuras, a partir da análise dos resultados deste estudo, investigar os processos de cuidado ao paciente oncológicos em hospitais gerais, bem como, a qualidade do gerenciamento do cuidado e capacidade de inovação, visando identificar possibilidades de superação deste problema, bem como, ampliar e diversificar os cenários de investigação.

\section{REFERÊNCIAS}

1. Brasil. Lei 7498 , de 25 de junho de 1986. Dispõe sobre a regulamentação do exercício da enfermagem, e dá outras providências. Brasília; 1986.

2. Nascimento LKAS, Medeiros ATN, Saldanha EA, Tourinho FSV, Santos VEP, Lira ALBC. Sistematização da assistência de enfermagem a pacientes oncológicos: uma revisão integrativa da literatura. Rev Gaúch Enferm. 2012;33(1):177-85.

3. Soares MI, Resck ZMR, Terra FS, Camelo SHH. Sistematização da assistência de enfermagem: facilidades e desafios do enfermeiro na gerência da assistência. Esc Anna Nery Rev Enferm. 2015;19(1):47-53. 


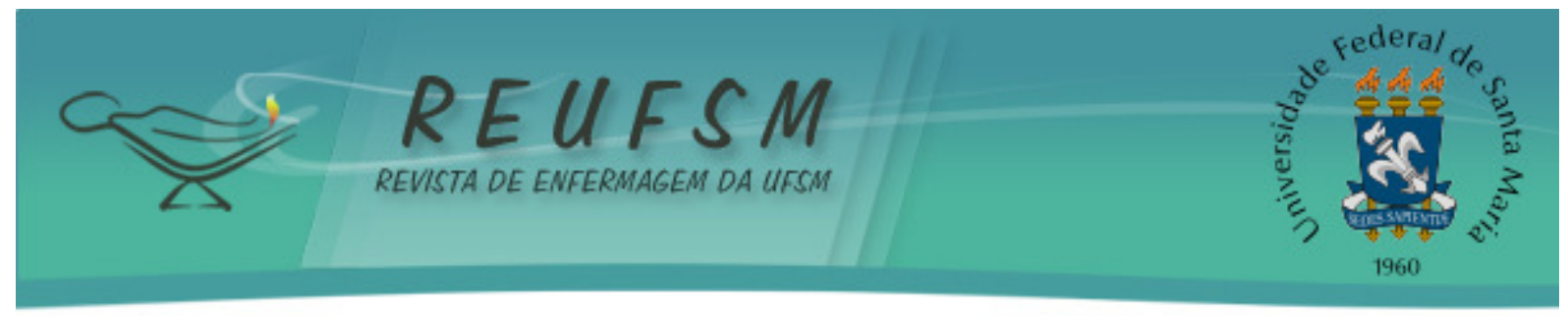

4. Silva JT, MAtheus MCC, Fustinoni SN, Gutiérrez MGR. Prática profissional de enfermeiras que cuidam de pacientes com câncer em hospitais gerais. Rev Bras Enferm. 2012;65(3):460-5.

5. Luz KR, Vargas MAO, Schmidtt PH, Barlem ELD, Tomaschewski-Barlem JG, Rosa LM. Problemas éticos vivenciados por enfermeiros oncológicos. Rev Latinoam Enferm. 2015;23(6):1187-94.

6. Strauss A, Corbin J. Pesquisa qualitativa: técnicas e procedimentos para o desenvolvimento de teoria fundamentada. $2^{\mathrm{a}}$ ed. Porto Alegre: Artmed; 2008.

7. Brasil. Ministério da Saúde. Resolução 196, de 10 de outubro de 1996. Aprova diretrizes e normas regulamentadoras de pesquisa envolvendo seres humanos. Diário Oficial da União, Brasília, 16 out. 1996; Seção 1, p. 59.

8. Moura GMSS, Inchauspe JAF, Dall'Agnol CM, Magalhães AMM, Hoffmeister LV. Expectativas da equipe de enfermagem em relação à liderança. Acta Paul Enferm. 2013;26(2):198-204.

9. Lanzoni GMM, Meirelles BHS. Liderança do enfermeiro: uma revisão integrativa da literatura. Rev Latinoam Enferm. 2011;19(3):[08 telas].

10. Santos JLG, Lima MADS, Pestana AL, Colomé ICS, Erdmann AL. Estratégias utilizadas pelos enfermeiros para promover o trabalho em equipe em um serviço de emergência. Rev Gaúch Enferm. 2016;37(1):e50178.

11. Guerra KJ, Spiri WC. Compreendendo o significado da liderança para o aluno de graduação em enfermagem: uma abordagem fenomenológica. Rev Bras Enferm. 2013;66(3):399-405.

12. Albuquerque PDSM, Araujo LZS. Informação ao paciente com câncer: o olhar do oncologista. Rev Assoc Med Bras. 2011;57(2):144-52.

13. Nunes MGS, Rodrigues BMRD. Tratamento paliativo: perspectiva da família. Rev Enferm UERJ. 2012;20(3):338-43.

14. Vicenzi A, Schwartz E, Cecagno D, Viegas AC, Santos BP, Lima JP. Cuidado integral de enfermagem ao paciente oncológico e à família. Rev Enferm UFSM. 2013;3(3):409-17.

15. Nascimento LA, Kreling MCGD. Avaliação da dor como quinto sinal vital: opinião de profissionais de enfermagem. Acta Paul Enferm. 2011;24(1):50-4.

16. Ferraz L, Vendruscolo C, Marmett S. Educação permanente na enfermagem: uma revisão integrativa. Rev Baiana Enferm. 2014;28(2):196-207.

Data de recebimento: 16/03/2016

Data de aceite: 19/08/2016

Contato do autor responsável: Caroline Cechinel Peiter. Universidade Federal de Santa Catarina, Campus Universitário, Departamento de Enfermagem, sala 518. Rua Engenheiro Agronômico Andrei Cristian Ferreira, s/n - Trindade, Florianópolis - SC, Brasil. CEP: 88040-900. carolcechinel@gmail.com. 